\title{
Shoulder impingement syndrome in relation to shoulder intensive work
}

\author{
Poul Frost, Johan Hviid Andersen
}

\begin{abstract}
Objectives-To analyse the risk of shoulder impingement syndrome relative to shoulder intensive work.

Methods-A cross sectional study of a historical cohort of 1591 workers employed between 1986 and 1993 at a slaughterhouse or a chemical factory. Workers not doing tasks in slaughtering or meat processing constituted the reference group. Intensity of shoulder work in meat processing tasks was assessed by video based observations. Information on shoulder disorders was collected by questionnaire and by physical examinations. Impingement syndrome was diagnosed when shoulder symptoms had been present for at least 3 months during the past year and there were signs of subacromial impingement in the corresponding shoulder at physical examination. Shoulder function was assessed at the same occasion with the Constant scoring technique. Prevalence of shoulder impingement syndrome was analysed according to job title and cumulative exposure.
\end{abstract}

Results-Prevalence ratio for shoulder impingement syndrome was 5.27 (95\% confidence interval (95\% CI), 2.09 to 12.26) among currently working and 7.90 (95\% CI, 2.94 to 21.18) among former slaughterhouse workers. Transformed model based prevalence ratios according to years in slaughterhouse work showed an overall association between cumulative exposure and risk for shoulder impingement syndrome.

Conclusions-This study supports the hypothesis that shoulder intensive work is a risk factor for impingement syndrome of the shoulder. Despite the historical cohort design healthy worker selection may have influenced the exposure-response relation found.

(Occup Environ Med 1999;56:494-498)

Keywords: historical cohort; rotator cuff syndrome; slaughterhouse workers

The evidence of work related risk factors for clinical based shoulder disorders, including shoulder tendinitis, has recently been evaluated. ${ }^{12}$ Work tasks that repetitively strain the shoulder joint and work with hands at or above acromion height are thought to be harmful. Due to repetitive impingement of the subacromial structures on the undersurface of the acromion, ${ }^{3}$ tendinitis and eventually degeneration and rupture of the supraspinatus tendon may result. Raising the arm above $30^{\circ}$ has been shown to increase intramuscular pressure in the supraspinatus muscle to an extent that may impair normal blood perfusion. ${ }^{4}$ Clinical shoulder disorders have also been related to cumulative exposure to vibration $^{5}$ and to repetitive work. ${ }^{67}$ Although current evidence suggests that repetitive work and work involving raising the arm confer a risk for shoulder disorders there is a need to corroborate the findings of the few small earlier studies. To contribute to the knowledge about shoulder intensive work as a risk factor for developing shoulder symptoms and clinical shoulder disorders we studied a historical cohort consisting of about 1600 workers with varying exposure to shoulder intensive work.

\section{Methods}

This is a cross sectional study of a historical cohort $^{8}$ of present and former workers employed between 1 January 1986 and 30 September 1993 at a slaughterhouse or a chemical factory. Information on duration of employment and the personal identification numbers were obtained from the company files. Vital status and current postal address were found by register linkage to the Danish central personal register. In all, 1591 subjects still alive and living in Denmark with at least 6 months of employment in the chosen period were identified and thus constituted the study population. At the slaughterhouse 1115 $(70.1 \%)$ subjects were identified and 476 $(29.9 \%)$ were identified at the chemical plant. Their mean (SD) age was 40.5 (12.2) years. Their mean (SD) duration of employment was 9.1 (7.6) years and $14.8 \%$ were women.

Information on exposure and health was collected with postal questionnaires, ergonomic observations of tasks and standardised physical examinations. Altogether 1141 people $(71.7 \%)$ responded to the questionnaire. Their mean (SD) age was 40.7 (11.7) years, mean (SD) duration of employment 9.5 (7.6) years, and $15.3 \%$ were women. From the slaughterhouse 99 workers working as repairmen or in other service jobs were allocated to the referent group, and 10 workers from the chemical factory, who had previously worked as slaughterhouse workers, were classified as slaughterhouse workers. Thus, $743(65.1 \%)$ of the participating workers were slaughterhouse workers with a mean (range) total experience in slaughterhouse work of 13 (1-46) years, and 398 $(34.9 \%)$ were referents. Table 1 shows some demographic characteristics and possible influences on impingement syndrome ${ }^{9}$ in the two groups. 
Table 1 Distribution of age, sex, and other characteristics with possible influence on the prevalence of impingement syndrome of the shoulder among referents and slaughterhouse workers

\begin{tabular}{lll}
\hline & $\begin{array}{l}\text { Referents } \\
(n=398)\end{array}$ & $\begin{array}{l}\text { Slaughterhouse } \\
\text { workers }(n=743)\end{array}$ \\
\hline Mean age (SD, y) & $42.2(12.2)$ & $39.9(11.3)$ \\
Mean BMI (SD, $\left.\mathrm{kg} / \mathrm{m}^{2}\right)$ & $25.5(3.8)$ & $25.4(4.04)$ \\
Ever smoker $(\%)$ & 78.9 & 75.1 \\
Female (\%) & 12.6 & 16.8 \\
Previous shoulder trauma (\%) & 4.3 & 4.6 \\
\hline
\end{tabular}

\section{EXPOSURE ASSESSMENT}

Information on employment was obtained from the questionnaire. Main exposure categories, slaughterhouse workers or referents, were defined according to whether the participants had ever worked in pig slaughtering or meat processing tasks. These tasks have been described in detail previously ${ }^{10}$ and characterised by being monotonous and highly intensive manually. Analysis of video recordings on 48 of these tasks (representing about $90 \%$ of the jobs held by slaughterhouse workers) showed that the upper arms were raised to at least $30^{\circ}$ for about half the working time (mean proportion of time with arms raised to at least $30^{\circ}$ was $48 \%$, and the arms were raised above $30^{\circ}$ about 10 times a minute). The stresses on shoulders did not differ substantially between departments in the slaughterhouse. Workers in the control group performed varied work which included light manual work, supervising automatic production of vegetable oil products at the chemical factory, or maintaining and repairing production equipment at the slaughterhouse. No observations were made of workers in the reference group, but self reported ergonomic stresses seemed to be different in the two groups. Repetitive manual movements were reported for at least half the day by $78 \%$ of slaughterhouse workers and by $15 \%$ of referents.

\section{HEALTH ASSESSMENT}

Self reported symptoms in the shoulder region for at least 3 months within the past year combined with a positive sign of impingement at physical examination was diagnostic for shoulder impingement syndrome. Information on musculoskeletal symptoms was collected with slightly modified questions from the Nordic questionnaire. ${ }^{11}$ Subjects reporting long lasting symptoms in their shoulders were selected for a standardised physical examination together with 110 randomly selected subjects without long lasting shoulder symptoms. The flow chart in figure 1 shows the participation in procedures to identify subjects with shoulder impingement syndrome and in procedures for validating the diagnostic procedure. The impingement sign was considered positive when pain at the anterolateral and superior aspect of the shoulder joint could be elicited or exacerbated by passive internal rotation of the arm in $90^{\circ}$ shoulder abduction in the plane of the scapula. ${ }^{12}$ The impingement sign was found to be positive in four of the 110 people without long lasting symptoms (3.6\%). Shoulder function was assessed as proposed by Constant. ${ }^{13}$ This total score (100 points) of shoulder function was made up of a score (up to 35 points) of two subjective variables (pain and activities of daily living) and (up to 65 points) of two objective variables (range of motion and shoul-

1141

Workers filled in questionnaire

843

Were slaughterhouse workers

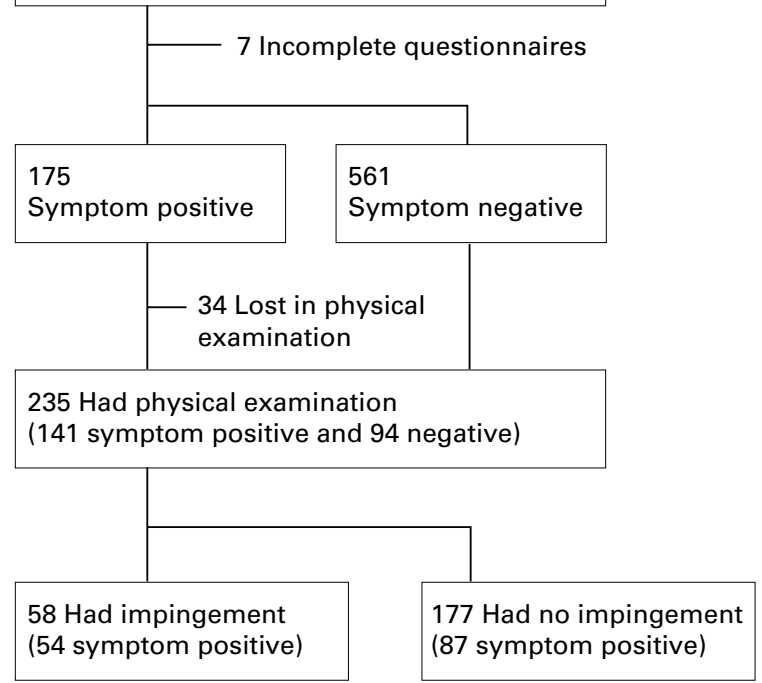

398

Were referents

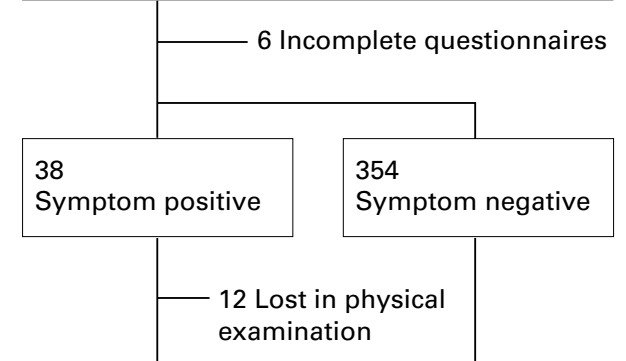

42 Had physical examination (26 symptom positive and 16 negative)

Figure 1 Flow chart: identification of subjects with shoulder impingement syndrome defined as self reported symptoms in the shoulder region for at least 3 months (symptom positive) combined with clinical signs of impingement and participation in procedures for validation of the diagnostic procedure. 
Table 2 PR of shoulder symptoms and impingement syndrome ${ }^{*}$ among current $(n=576)$ and formert $(n=167)$ slaughterhouse workers (SHWs) $v$ referents $(n=398)$

\begin{tabular}{|c|c|c|c|c|c|c|c|c|}
\hline & \multicolumn{2}{|c|}{$\begin{array}{l}\text { Pain and discomfort within the past } \\
12 \text { months }\end{array}$} & \multicolumn{2}{|c|}{$\begin{array}{l}\text { Pain and discomfort within the past } \\
\text { week }\end{array}$} & \multicolumn{2}{|c|}{ Pain and discomforrt for $\geqslant 3$ months } & \multicolumn{2}{|c|}{ Impingement syndrome } \\
\hline & Obs (\%) & $P R(95 \% C I)$ & Obs $(\%)$ & $P R(95 \% C I)$ & Obs (\%) & $P R(95 \% C I)$ & Obs (\%) & $P R(95 \% C I)$ \\
\hline Referents & $140(35.4)$ & $1(-)$ & $83(21.4)$ & $1(-)$ & $38(9.7)$ & $1(-)$ & $5(1.3)$ & $1(-)$ \\
\hline Current SHW & $351(60.9)$ & $1.72(1.48$ to 1.99$)$ & $224(40.7)$ & $1.90(1.53$ to 2.36$)$ & $134(23.5)$ & $2.42(1.73$ to 3.40$)$ & $38(6.9)$ & $5.27(2.09$ to 13.26$)$ \\
\hline Former SHW & $82(49.1)$ & $1.39(1.13$ to 1.70$)$ & $50(31.6)$ & 1.48 (1.09 to 1.99$)$ & $41(24.7)$ & $2.56(1.70$ to 3.81$)$ & $16(10.4)$ & 7.90 (2.94 to 21.18$)$ \\
\hline
\end{tabular}

*Pain of the shoulder region for $\geqslant 3$ months within the past year combined with signs of subacromial impingment at physical examination.

†Slaughterhouse workers who had been out of work for the previous 3 months.

der strength). A high score reflects good shoulder function. Points are subtracted according to the degree of impairment. In the present study controlled muscle strength of the shoulder was analysed with a portable microprocessor $^{14}$ (Isobex 2.1 by Cursor AG, Bern, Switzerland) recording the mean strength of three repeated measurements of 3 seconds each. Computing the Constant score each $\mathrm{kg}$ was allocated 2 points up to 25 points given for strength of at least $12 \mathrm{~kg}$. Examinations were carried out by the authors without knowledge of the answers in the questionnaire and shoulder strength was assessed blinded to the results of the physical examination.

\section{STATISTICS}

Prevalence ratios for shoulder symptoms and impingement syndrome and their $95 \%$ confidence intervals (95\% CIs) were estimated comparing current and former slaughterhouse workers with referents. For exposure-response analysis the relation between cumulative exposure (years in slaughterhouse work) and impingement syndrome was evaluated by multiple logistic regression analysis. Product terms between age and cumulative exposure, sex (female or male), previous shoulder accident (yes or no), smoking (current, former, or

Table 3 Estimated variables (SEMs) by multiple logistic regression analysis with linear, squared, and quadratic terms of cumulative exposure in slaughterhouse work and age in the final model

\begin{tabular}{lll}
\hline & Regression coefficient & SEM \\
\hline Cumulative exposure: Years $^{1}$ & & \\
Years $^{1 / 2}$ & -0.324 & 0.137 \\
Years $^{2}$ & 1.539 & 0.490 \\
Age & 0.004 & 0.002 \\
& 0.056 & 0.015 \\
\hline
\end{tabular}

Intercept $=-6.832($ SEM 0.849)

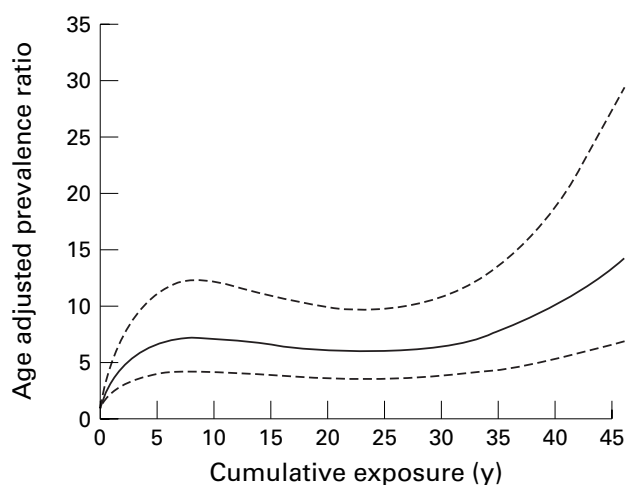

Figure 2 Age adjusted prevalence ratios of shoulder impingement syndrome (shoulder pain for at least 3 months combined with clinical sign of impingement) by cumulative exposure. Model based estimates (95\% CIs). never), and body mass index $\left(\geqslant 30 \mathrm{~kg} / \mathrm{m}^{2}\right.$, $25-30 \mathrm{~kg} / \mathrm{m}^{2} v<25 \mathrm{~kg} / \mathrm{m}^{2}$ ) were examined as well, but did not contribute significantly to the model. The final model included the linear, squared, and quadratic terms of cumulative exposure to allow for information within categories ${ }^{15}$ and age. Given the estimated coefficients an age adjusted smoothed curve of prevalence ratios across levels of cumulative exposure was estimated. ${ }^{16}$ Age was kept comparable by replacing the actual age by the value for cumulative exposure and adding 13 years to this value.

Information about criteria defining impingement syndrome was missing for 59 subjects $(5.2 \%$, (fig 1$)$. These subjects were excluded from the analysis.

Among participants at the physical examination right sided shoulder function and strength were described for men and women in groups without symptoms, with symptoms, and with signs of impingement in their right shoulder. Paired comparisons of differences in shoulder function and strength were carried out in groups without long lasting symptoms and in subgroups with unilateral shoulder symptoms or clinical sign of impingement.

\section{Results}

Table 2 shows that the prevalence of self reported shoulder symptoms and impingement syndrome are higher among current and former slaughterhouse workers than among referents. Also, it was found that the prevalence ratios differ substantially depending on the chosen outcome measure. The highest prevalence ratio for impingement syndrome was among former slaughterhouse workers. Table 3 shows adjusted variables for impingement syndrome according to linear, squared, and quadratic terms of cumulative exposure and age. Figure 2 shows the model based estimates of prevalence ratios for each level of cumulative exposure. The risk estimate increases steeply within the first 5-6 years of cumulative exposure and then tends to flatten after 9 years until a new increase gradually develops after about 25 years of cumulative exposure.

The analyses of shoulder function showed a decrease in all functional measures among participants with long lasting symptoms and even more among participants with a clinical diagnosis (table 4). The paired comparisons of affected and unaffected shoulders in the subgroup with unilateral affection showed a substantial reduction in functional score, indicating quite serious impairment in the group 
Table 4 Shoulder function among participants ${ }^{\star}$ at physical examination according to severity of right shoulder disorder: mean constant scoret, subscores, strength, and paired comparisons in healthy people and people with unilateral symptoms or impingement sign

\begin{tabular}{|c|c|c|c|c|c|c|}
\hline & $\begin{array}{l}\text { Total score } \\
\text { points (SD) }\end{array}$ & $\begin{array}{l}\text { Pain and activities } \\
\text { points }(S D)\end{array}$ & $\begin{array}{l}\text { Range of motion } \\
\text { points (SD) }\end{array}$ & $\begin{array}{l}\text { Strength } \\
\mathrm{kg}(S D)\end{array}$ & $\begin{array}{l}\text { Difference in total score points } \\
(95 \% \mathrm{CI})\end{array}$ & $\begin{array}{l}\text { Difference in strength } \\
\mathrm{kg}(95 \% \mathrm{CI})\end{array}$ \\
\hline \multicolumn{7}{|l|}{ Men: } \\
\hline Healthy $(n=100)$ & $93.5(6.9)$ & $33.3(3.6)$ & $39.3(1.4)$ & $10.7(2.5)$ & - & - \\
\hline Symptoms $(\mathrm{n}=76)$ & $88.9(8.6)$ & $31.0(3.6)$ & $38.6(2.2)$ & $9.7(2.7)$ & - & - \\
\hline Impingement $(n=47)$ & $63.8(17.7)$ & $20.5(6.6)$ & $31.4(8.1)$ & $5.9(3.0)$ & - & - \\
\hline \multicolumn{7}{|l|}{ Women: } \\
\hline Healthy $(n=26)$ & $85.7(5.9)$ & $24.1(3.6)$ & $39.8(0.9)$ & $5.9(1.5)$ & - & - \\
\hline Symptoms $(n=16)$ & $78.4(8.1)$ & $29.1(4.3)$ & $39.2(1.7)$ & $5.1(1.8)$ & - & - \\
\hline Impingement $(n=7)$ & $63.3(10.2)$ & $20.7(3.4)$ & $34.6(8.1)$ & $4.3(1.4)$ & - & - \\
\hline \multicolumn{7}{|l|}{ Unilateral: } \\
\hline Healthy $(n=101)$ & - & - & - & - & $0.4(-1.5$ to 0.7$)$ & $0.1(-0.1$ to 0.4$)$ \\
\hline Symptoms $(n=33)$ & - & - & - & - & $-6.0(-3.3$ to -8.6$)$ & $-0.5(-1.1$ to 0.1$)$ \\
\hline Impingement $(n=23)$ & - & - & - & - & $-22.3(-16.7$ to -28.0$)$ & $-2.5(-1.3$ to -3.7$)$ \\
\hline
\end{tabular}

${ }^{\star}$ Functional measures were incomplete for five subjects.

†Normal scores of shoulder function were constructed at add up to 100 points. In this study strength was measured using a dynamometer giving lower values than reported by Constant with a spring balance. ${ }^{13}$

with long lasting symptoms and clinical signs of subacromial impingement.

\section{Discussion}

Our increased risk of shoulder symptoms and impingement syndrome among present and former slaughterhouse workers supports the hypothesis that prolonged shoulder intensive work is a risk factor for developing periarticular shoulder disorders. We found that slaughterhouse workers are exposed to both repetitive shoulder movements and sustained arm elevation. Further the tasks implied vigorous use of knifes and repetitive handling of meat products weighing 5-12 kg each. If these combined exertions and their responses in the tissues are long lasting it has been argued that inflammation, degeneration, and eventually rupture of shoulder tendons may result. ${ }^{17}$ Due to similar exertions within and between tasks dealing with pig slaughtering and meat processing, the combined stresses on the shoulders in practically all slaughterhouse workers in this study are probably at the same high level, but the duration of slaughterhouse work varied from 1 to 46 years and there was an overall increase in risk with cumulative exposure. The pattern was, however, fluctuating, and showed an increase during the first 5-8 years, levelling off at around that level and then increased again after about 25 years of cumulative exposure. As subjects who had left the company before 1986 were not included in the cohort, selection related to shoulder disorders could have influenced the risk estimates among subjects with intermediate levels of cumulative exposure. The risk of impingement syndrome was highest among former slaughterhouse workers indicating that selection mechanisms may be important. Another factor with a possible influence on the risk estimates is our definition of shoulder disorder, which can cover a wide range of underlying diseases and thus probably include disorders which do not have similar prognoses. The mean duration of disease will most likely increase with cumulative exposure. In this study risk estimates are based on prevalent cases and therefore depend on both disease duration and incidence. This means that risk estimates may also reflect prognosis of the disorder.

Due to common knowledge about the working conditions at Danish slaughterhouses, it is possible that workers with musculoskeletal disorders avoid employment in this industry. This selection is probably strengthened by the fact that a 3 month trial period before permanent employment is usual. These primary selection factors are expected to cause underestimation of the risk as at least 6 months of employment was an inclusion criterion. The historical cohort design was used in an attempt to avoid underestimation due to secondary selection mechanisms.

Classification of shoulder impingement syndrome was based on a combination of long lasting symptoms and a positive outcome of the test for signs of impingement. For practical reasons physical examinations were carried out unblinded for the employing company, but blinded to symptoms, exact age, and cumulative exposure. Also, the analyses showed that diagnosed cases had impairment of normal shoulder function and very few subjects without symptoms had signs of impingement. This suggests that there is little misclassification of cases.

There have been few other studies of work related clinical shoulder problems. One of these was on Finnish slaughterhouse workers. ${ }^{18}$ Three cases of supraspinatus and one case of biceps tendinitis were found among 113 workers, but the mean duration of employment was short. Two studies point to the importance of cumulative exposure. In a historical cohort of sewing machine operators the risk of shoulder disorder (rotator cuff syndrome) increased with increasing seniority in employment, ${ }^{6}$ and also rockblasters, exposed to combined exposures of vibration, heavy lifting, and static work postures, showed positive associations between shoulder tendinitis and cumulative exposure. ${ }^{5}$ However, the interpretation of exposureresponse patterns in disorders with fluctuating durations that are based on prevalence estimates are not straightforward.

In conclusion, we found that the results of this study support the hypothesis that sustained intensive work that stresses the shoulders as much as in a Danish slaughterhouse is a risk factor for developing impingement syndrome characterised by functional impairment of the affected shoulder. The risk substantially increases after a few years of experience and tends to increase further with cumulative 
exposure. Selection mechanisms and differences in mean duration of the underlying shoulder disorders may, however, have influenced the dose-exposure patterns. To prevent work related shoulder disorders exposure time should be reduced, especially in tasks in which combinations of force, repetition, and sustained arm elevation are hard to prevent.

We thank the Danish Working Environment Fund who funded the study.

1 Hagberg M, Silverstein B, Wells R, et al. Evidence of work relatedness for selected musculoskeletal disorders of the neck and limbs. In: Kourinka I, Forcier L, editors. Work related musculoskeletal disorders (WMSDs): a reference book for prevention. London: Taylor and Francis, 1995.

2 Bernard BP, ed. Musculoskeletal disorders and workplace factors. A critical review of epidemiologic evidence for work-related musculoskeletal disorders of the neck, upper extremity, and low back pain. Washington, DC: Department of Health and Human Services (National Institute for of Health and Human Services (National Institute for

3 Neer CS, II. Impingement lesions. Clin Orthop 1983;173: $70-7$

4 Järvholm U, Styf J, Suurkula M, et al. Intramuscular pressure and muscle blood flow in the supraspinatus. Eur $\mathcal{F} A p p l$ Physiol 1988;58:219-24.

5 Stenlund B, Goldie I, Hagberg M, et al. Shoulder tendinitis and its relation to heavy manual work and exposure to vibration. Scand $\mathcal{F}$ Work Environ Health 1993;19:43-9.

6 Andersen JH, Gaardboe O. Musculoskeletal disorders of the neck and upper limb among sewing machine operators: a clinical investigation. Am F Ind Med 1993;24:689-700.
7 Ohlsson K, Hansson G-Å, Balogh I, et al. Disorders or the neck and upper limbs in women in the fish processing neck and upper limbs in women in the fish

8 Checkoway H, Pearce N, Dement JM. Design and conduct of occupational epidemiology studies: I. design aspects of cohort studies. Am F Ind Med 1989;15:363-73

9 Winkel J, Westgaard R. Occupational and individual risk factors for shoulder-neck disorders: Part II. The scientific basis (literature review) for the guide. International fournal of Industrial Ergonomics 1992;10:85-104.

10 Frost P, Andersen JH, Nielsen VK. Occurrence of carpal tunnel syndrome among slaughterhouse workers. Scand $\mathcal{F}$ Work Environ Health 1998;24:285-92.

11 Kourinka I, Jonsson B, Kilbom Å, et al. Standardized Nordic questionnaires for the analysis of musculoskeletal symptoms. Applied Ergonomics 1987;18:233-7.

12 Iannotti JP. Clinical evaluation of the painful shoulder. In: Zlatkin MB, ed. MRI of the shoulder. New York: Raven Press, 1991

13 Constant CR. Historical background, anatomy and shoulder function. In: Hazleman BL, Dieppe PA, eds. Baillière's clinical rheumatology. International practice and research. London: Baillière Tindall, 1989.

14 Gerber C. Integrated scoring systems for the functional assessment of the shoulder. In: Matsen F, Fu FH, Hawkins RJ, eds. The shoulder: a balance of mobility and stability. The American Academy of Orthopaedic Surgeons 1993:531-50.

15 Greenland S. Dose-response and trend analysis in epidemiology: alternatives to categorical analysis. Epidemiology 1995;4:356-65.

16 Greenland $S$ Introduction to regression modeling. In: Rothman KJ, Greenland S, eds. Modern epidemiology, 2nd ed. Philadelphia: Lippincott-Raven, 1998.

17 Armstrong TJ, Buckle P, Fine LJ, et al. A conceptual model for work-related neck and upper limb musculoskeletal disorders. Scand $\mathcal{F}$ Work Environ Health 1993;19:73-84.

18 Viikari-Juntura E. Neck and upper limb disorders among slaughterhouse workers. An epidemiologic and clinic study. Scand $\mathcal{f}$ Work Environ Health 1983;9:283-90. 